\title{
ESTUDO DO COEFICIENTE DE PERMEABILIDADE EM ENSAIOS DE POÇO PELO PADRÃO ABGE: COMPLEXO ALCALINO CARBONATÍTICO DO BARREIRO (CACB), ARAXÁ-MG
}

\section{Tiago Antônio Torres Gomes ${ }^{1} \&$ Kely Sehn da Costa ${ }^{1}$}

Resumo. O conhecimento do coeficiente de permeabilidade (K) de um solo é de suma importância em estudos de vários cunhos, sobretudo naqueles relacionados ao fluxo de água subterrânea, auxiliando na caracterização do meio pelo qual esta percola. $O$ objetivo deste trabalho foi caracterizar, por meio de ensaios de permeabilidade pelo padrão ABGE, o alterito laranja mineralizado ao nióbio, relacionado ao Complexo Carbonatítico Alcalino do Barreiro, com vistas a gerar subsídios para a caracterização hidrogeológica do minério. Os valores de $\mathrm{K}$ foram obtidos pelo método de Hvorslev e apresentaram valores muito próximos, variando de $10^{-4}$ a $10^{-5} \mathrm{~cm} / \mathrm{s}$. O método de ensaio mostrou-se adequado para o material testado, que foi classificado como areias finas siltosas e argilosas e siltes argilosos.

Palavras Chave: Coeficiente de permeabilidade, teste de infiltração, padrão ABGE.

Abstract. The Knowledge of the permeability coefficient $(K)$ of the soil is very important in several types of studies, particularly those related to groundwater flow, assisting in the material characterization. The objective of this study was to characterize, using the ABGE infiltration tests, the niobium mineralized alterite, in order to generate data for hydrogeological characterization of the ore. The $K$ values were obtained by Hvorslev method and showed very close values varying from $10^{-4}$ to $10^{-5} \mathrm{~cm} / \mathrm{sec}$. The test method was suitable for the material tested, which was classified as fine silty and clayey sands and clayey silts.

Keywords: permeability coefficient, infiltration test, ABGE Standards.

\footnotetext{
${ }^{1}$ CBMM- Companhia Brasileira de Metalurgia e Mineração - Córrego da Mata S/N - Caixa Postal 8 - Araxá - MG (34)3669-3587.www.cbmm.com.br; tiago.gomes@cbmm.com.br; kely.costa@cbmm.com.br
} 


\section{INTRODUÇÃO}

A importância do estudo da percolação da água no solo reside no fato de que esta interfere num grande número de problemas práticos, tais como drenagem superficial, rebaixamento do nível de água subterrânea, cálculo de vazões, análise de recalques, estudos de estabilidade de taludes, etc.

A permeabilidade pode ser definida como sendo a propriedade que o solo apresenta de permitir o escoamento da água através dele, sendo o grau de permeabilidade expresso numericamente pelo coeficiente de permeabilidade $(\mathrm{K})$. A permeabilidade é uma das propriedades do solo com maior faixa de variação de valores e é função de diversos fatores, dentre os quais podemos citar o índice de vazios, temperatura, estrutura do solo, grau de saturação e estratificação do terreno. Como estes parâmetros estão, geralmente relacionados, a modelagem e compreensão do fenômeno complicam-se ainda mais.

Segundo Libardi (2000) há carência de estudos da dinâmica da água no que diz respeito a condições não-saturadas. Para avaliação destes fluxos, as propriedades hidráulicas da zona nãosaturada precisam comumente ser estimadas.

Nesse sentido, foram realizados testes que possibilitaram reconhecer o coeficiente de permeabilidade na mina de nióbio da CBMM em sua porção NW, mais especificamente no banco de cota 1080, acima do nível de água subterrânea.

Este trabalho foi desenvolvido com vistas a auxiliar na elaboração do plano de drenagem superficial da mina, bem como reconhecer a permeabilidade dos solos na zona vadosa, a qual será utilizada como parâmetro hidrodinâmico na construção de um modelo de fluxo tridimensional no âmbito da mina.

Foram realizados seis testes de infiltração a carga variável, utilizando-se o método proposto pela ABGE - Associação Brasileira de Geologia de Engenharia (1996), no qual a avaliação da infiltração da água num furo de dimensões conhecidas é feita ao longo do tempo.

\section{SÍNTESE DA FUNDAMENTAÇÃO TEÓRICA}

Os primeiros estudos do coeficiente de permeabilidade foram realizados em 1857, pelo engenheiro francês Henry Darci, que constatou o grau de facilidade do escoamento de água pelos vazios de um meio poroso (FRANCIS, 1980). 
De acordo com Souza Pinto (2000), o coeficiente de permeabilidade indica a velocidade de percolação da água quando o gradiente hidráulico é igual à unidade. Esta velocidade, também chamada de velocidade de descarga é calculada dividindo-se a vazão pela área, no caso de um permeâmetro. A velocidade real é obtida dividindo-se a velocidade de percolação pelo índice de vazios do solo estudado.

A validade da Lei de Darci foi testada e validada para a maioria dos tipos de escoamento em solos. Entretanto, ela é inválida para o escoamento de líquidos em velocidades muito altas e para o escoamento de gases em velocidades muito baixas ou altas. O coeficiente de permeabilidade apresenta valores que variam desde $10^{-1} \mathrm{~m} / \mathrm{s}$ para seixos e pode ser inferior a $10^{-9} \mathrm{~m} / \mathrm{s}$ para argilas (LAMBE e WHITMAN, 1979).

Para Stephens (1996), a velocidade de percolação, na zona não saturada, varia em função das propriedades do meio poroso, das características do fluido e do teor de umidade volumétrica do material.

A determinação de K por meio de ensaios em laboratórios proporciona maior controle, porém exige inúmeros cuidados na retirada de amostras representativas do solo que se deseja estudar.

Segundo Souza Pinto (2000) e Lambe e Whitman (1979), os ensaios de campo são menos precisos, devido ao elevado número de variáveis envolvidas, mas são realizados no solo em sua situação real.

De acordo com Barbassa (2009), o tempo de umedecimento do solo antes do início dos ensaios de campo podem provocar grandes alterações do valor de K. Ainda segundo Barbassa (2009), determinação de K em campo é, de forma geral, bastante dificultada, seja porque os trabalhos são muito antigos, seja pela complexidade intrínseca do escoamento em condições incertas.

Vários são os métodos disponíveis na literatura especializada, destinados à quantificação da condutividade hidráulica "in situ”. A escolha adequada de um determinado método dependerá das características do solo e das condições do local a ser estudado (BANTON, 1993).

O método do permeâmetro Guelph talvez seja um dos mais aceitos e o mais rápido no procedimento de ensaio, fácil execução e cálculo, de maior exatidão e de menor perturbação no solo (RAGAB e COOPER, 1990).

Outro método bastante difundido é o do infiltrômetro de anéis concêntricos. Este equipamento consiste em dois cilindros metálicos de $3 \mathrm{~mm}$ de espessura e $30 \mathrm{~cm}$ de altura, com diâmetros de 30 e 
$50 \mathrm{~cm}$, com uma das bordas biseladas para facilitar a cravação no solo. Os cilindros são instalados à percussão (FABIAN e OTTONI, 1997). Para a realização do ensaio, preenche-se o cilindro interno com uma lâmina de 7,5cm de altura de águ. Entre os cilindros interno e externo a altura deve ser de $5 \mathrm{~cm}$. Utilizando-se de uma régua graduada, o posicionamento do nível é lido em vários intervalos de tempo, propiciando o cálculo do coeficiente de permeabilidade.

A Câmara de Fluxo é, basicamente, um cilindro metálico de aço inox, com 1mm de espessura, diâmetro de $80 \mathrm{~cm}$ e altura de $80 \mathrm{~cm}$. A cravação no solo é feita por pressão, exercida por macaco hidráulico de 10 T e conta, também, com o auxílio de um sistema de contra pesos e de uma mesa de cravação. A câmara deve ser cravada a $70 \mathrm{~cm}$ de profundidade e o ensaio de permeabilidade com a câmara de fluxo, é realizado seguindo-se as mesmas rotinas do infiltrômetro de anel duplo.

Os testes de permeabilidade em poço, seguindo o padrão ABGE, mostram-se vantajosos, uma vez que, não são necessários equipamentos específicos para a sua realização.

\section{1 - Execução de ensaio de permeabilidade padrão ABGE}

Em janeiro de 1981 foram editadas pela primeira vez, pela ABGE - Associação Brasileira de Geologia de Engenharia, as orientações para execução de ensaios de permeabilidade em solos no campo. Após o esgotamento da segunda e terceiras edições, devido à grande aceitação no meio técnico, foi lançada a quarta edição revisada e atualizada em 2013. O ensaio de poço invertido, segundo ABGE (2013) é realizado acima do nível do lençol freático, na zona vadosa realizando-se segundo os procedimentos descritos no item 3.

Calduro e Dorfman (s/d) descrevem um método que se assemelha ao da ABGE, exceto pelo tempo de umedecimento inicial e o número de repetições do ensaio.

O método usado na Grã-Bretanha, de acordo com Pratt et al.(1992), apud Baptista et al. (2005), a capacidade de absorção é estimada pelo tempo de injeção de água de modo que o seu nível passe de $75 \%$ para $25 \%$ da profundidade do ensaio.

\section{MATERIAIS E MÉTODOS}

\section{1 - Procedimentos do ensaio de campo}

Os testes de infiltração a carga variável foram realizados em campo segundo os procedimentos definidos pela ABGE (2013), descritos sucintamente abaixo: 
- Posicionar o trado no local a ser realizado o ensaio. A perfuração poderá ser auxiliada com a ferramenta "boca de lobo", caso seja necessário;

- Efetuar perfuração do solo, no domínio da zona vadosa - acima do nível freático natural (ABGE, 1996 - ensaio de infiltração a carga variável), mediante um furo de geometria cilíndrica (coeficiente “i”=5), com $25 \mathrm{~cm}$ de profundidade e $11 \mathrm{~cm}$ de diâmetro. Após sua execução, medir a profundidade e o diâmetro do furo, e anotar as respectivas medidas na planilha. Caso as medidas apresentem-se diferentes, considerá-las no ensaio, já que efetivamente reais - ex.: profundidade de $30 \mathrm{~cm}$ (no máximo) e diâmetro de $12 \mathrm{~cm}$ (ou mais);

- Efetuar a descrição litológica e granulométrica do material perfurado, ao longo dos $25 \mathrm{~cm}$ de profundidade do furo, com respectiva anotação em planilha;

- Encher o furo com água, para a saturação do solo no entorno do furo, até a formação de um “anel” de saturação. O nível d'água no furo deve ser mantido à superfície do terreno, visando a saturação do solo, para adequada execução do ensaio. Caso o solo apresente alta capacidade de infiltração, com um consumo de água elevado, sem ocorrer a saturação do terreno ao redor do furo, deverá ser continuada a introdução de água no furo até se atingir adequado nível de saturação, observando-se uma zona úmida (anel), molhada, no entorno do furo;

- Após verificada a saturação do solo, fixar na horizontal uma pequena tala transversal ao furo, rígida, para referência de nível (nível zero, inicial do ensaio, relativo ao tempo zero) com o enchimento do furo com água.

- Encher o furo com água, acima do nível de referência (zero), observando-se a infiltração e o consequente decréscimo do nível d'água no furo - quando atingido o nível zero de referência (indicado pela tala transversal ao furo), se inicia a contagem - tempo zero - com o cronômetro, estabelecendo-se a contagem dos tempos consecutivos das medições do decréscimo do nível de água no furo, com a régua milimetrada;

- A contagem do tempo das medições de rebaixamento do nível d'água no furo poderá ser efetuada a intervalos pré-determinados e consecutivos de 30' '(segundos); 1' (minuto); 1,5';

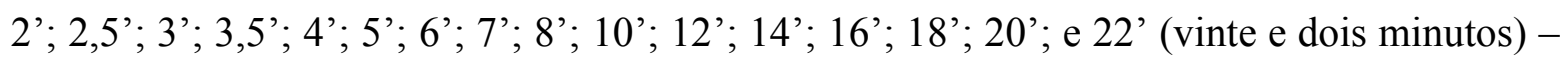
período do ensaio geralmente previsto; procedendo-se as respectivas anotações em planilha, com o registro do decréscimo do nível d'água no furo, a cada intervalo de tempo supra referido;

- O ensaio será dado por concluído após os 22' transcorridos, ou quando o furo secar totalmente; 
- Caso a capacidade de infiltração do solo seja muito baixa, o ensaio poderá ser prolongado, por exemplo, até 120 minutos;

- Anotar todos os resultados na planilha de ensaio.

\section{2 - Localização dos ensaios}

A jazida de nióbio da CBMM está situada a aproximadamente a $10 \mathrm{~km}$ ao sul da cidade de Araxá-MG e pode ser acessada pela rodovia MG 428, que liga Araxá à cidade de Franca, em São Paulo (FIGURA 1).

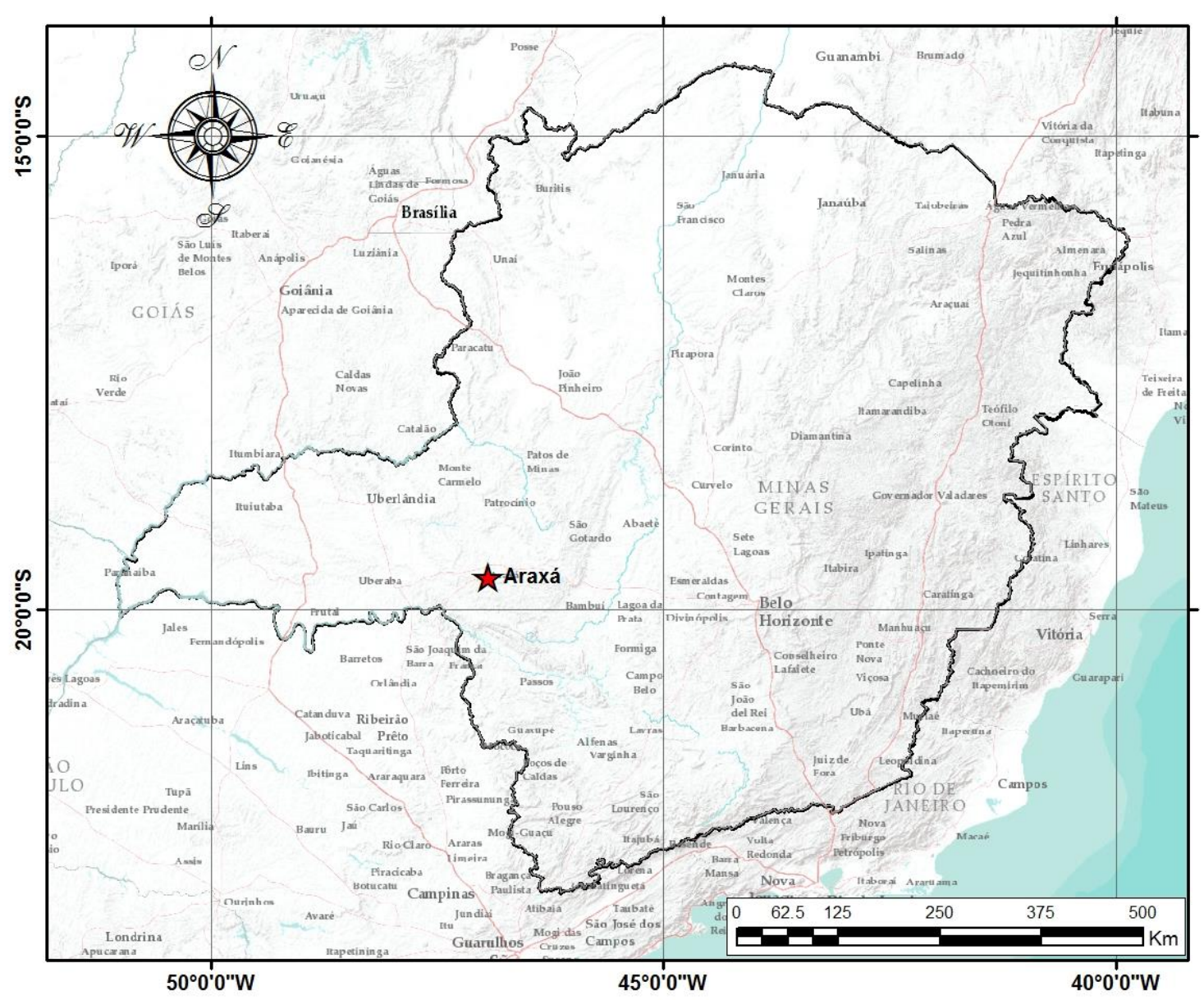

Figura 1 - Localização das atividades das CBMM.

A localização dos furos foi obtida com o uso de um GPS Garmin 62s e pode ser observada no mapa da figura 2. 


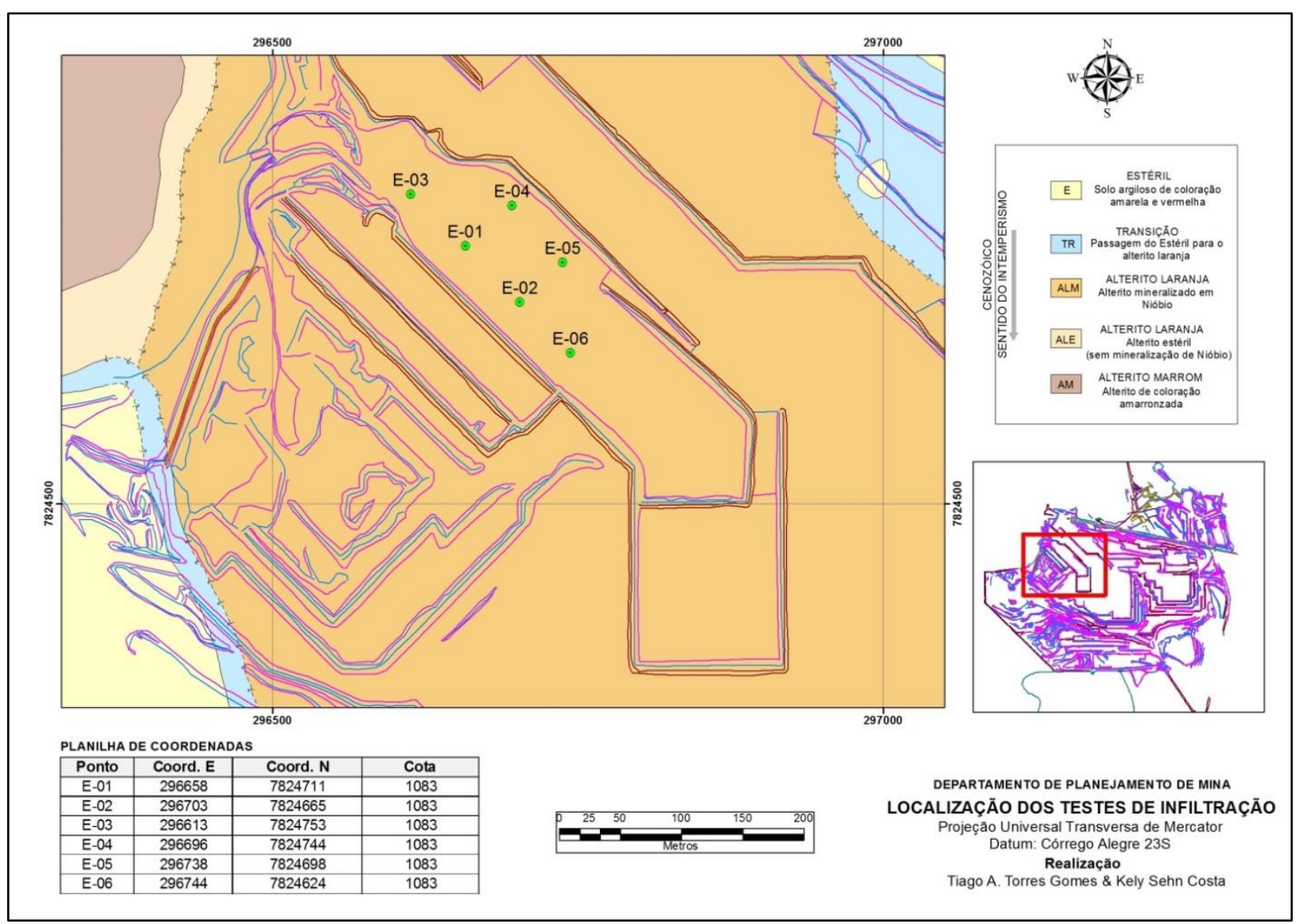

Figura 2 - Mapa de localização dos testes realizados

Foram perfurados seis poços para os ensaios de permeabilidade, distantes $50 \mathrm{~m}$ um do outro.

As amostras deformadas retiradas durante a perfuração do poço foram descritas do ponto de vista visual e textural e as suas características foram anotadas na planilha de cada teste.

\section{3 - Tempo de umedecimento prévio ao ensaio}

Os tempos de umedecimento inicial recomendados variam de acordo com cada autor. $\mathrm{O}$ método proposto pela ABGE (2013) recomenda a saturação do furo por 10 minutos. Este tempo foi respeitado para todos os ensaios e as leituras somente começaram a ser realizadas após este procedimento.

A figura 3 mostra as condições de campo para o teste, evidenciando o anel de saturação (A) e o procedimento de medição do descenso da água dentro do furo (B). 

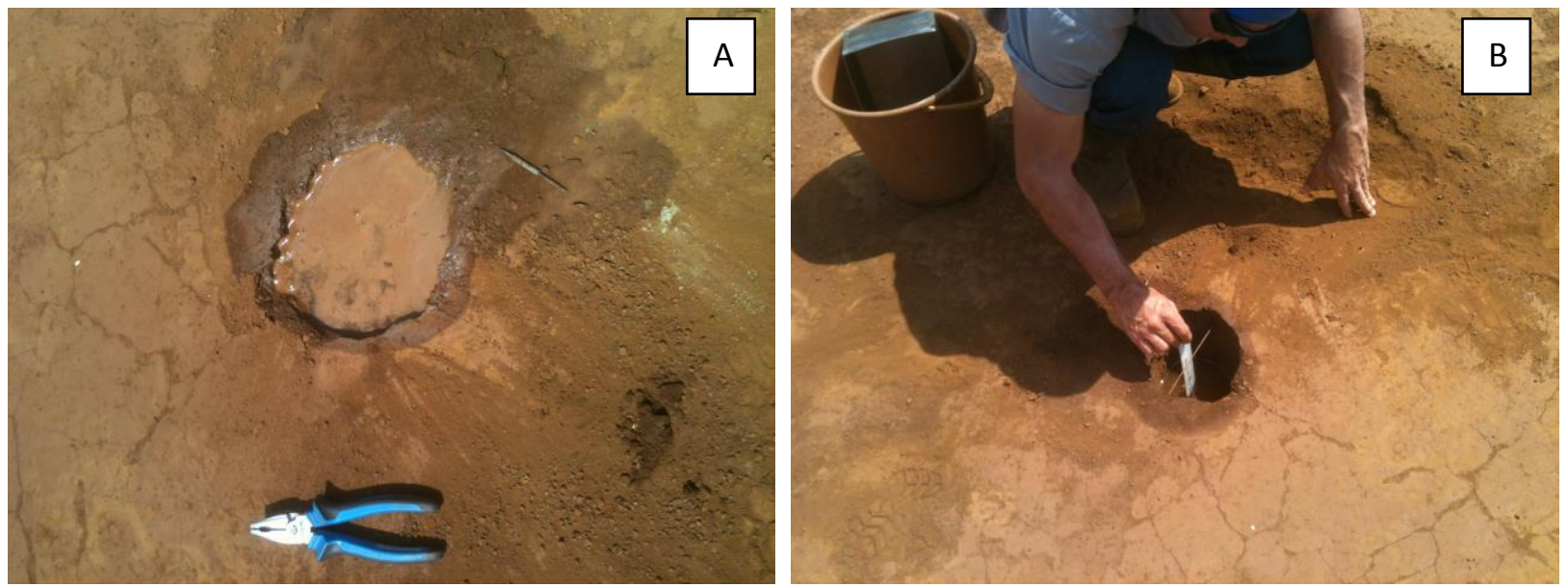

Figura 3 - Condições de campo para os testes de permeabilidade. (A) anel de saturação após 10 min. (B) Procedimento de leitura.

\section{4 - Método de Cálculo do Coeficiente de Permeabilidade}

O cálculo para a determinação do coeficiente de permeabilidade é feito de acordo com a seguinte equação (1) (ABGE, 2013):

$$
k=\frac{\Delta h}{\Delta t} \times \frac{1}{i\left(\frac{2 h}{r}+1\right)}
$$

Onde:

$\mathrm{K}=$ coeficiente de permeabilidade $(\mathrm{cm} / \mathrm{s})$

$\Delta \mathrm{h} / \Delta \mathrm{t}=$ Variação da altura medida em função do tempo $(\mathrm{cm} / \mathrm{s})$

$\mathrm{i}=$ constante geométrica do cilindro (igual a 5)(adimensional)

$\mathrm{r}=$ raio do furo $(\mathrm{cm})$

$\mathrm{h}=$ altura do furo $(\mathrm{cm})$

Cada resultado obtido foi comparado com a tabela da figura 3, proposta por Mello e Teixeira (1967). Esta tabela traz a permeabilidade como uma estimativa da ordem de grandeza, relacionada com a granulometria do material. 


\begin{tabular}{|c|c|c|c|c|c|}
\hline $\mathrm{K}(\mathrm{cm} / \mathrm{s})$ & $10^{2}$ & 1 & $10^{-2}$ & 1 & $10^{-6}$ \\
\hline SOLO & pedregulhos & areias & $\begin{array}{c}1 \\
\text { areias finas siltosas e } \\
\text { argilosas, siltes argilosos }\end{array}$ & argilas \\
\hline
\end{tabular}

Figura 4 - Classificação granulométrica segundo o coeficiente de permeabilidade (MELLO e TEIXEIRA, 1967)

As planilhas de cálculo devidamente preenchidas podem ser vistas no ANEXO I.

\section{APRESENTAÇÃO E DISCUSSÃO DOS RESULTADOS}

O material amostrado na execução de cada poço apresenta-se como um solo residual, produto da alteração da rocha carbonatítica do CACB, mineralizado em nióbio, com uma assembleia mineralógica composta por bariopirocloro (pandaíta), limonita, barita, magnetita, monazita, gorceixcita, ilmenita e quartzo (ISSA FILHO, 2005). O minério residual amostrado é localmente denominado alterito laranja e apresenta uma coloração amarronzada, com granulometria variando entre areais finas a muito finas, com porções mais ou menos siltosas.

Os resultados obtidos com os testes de permeabilidade apresentaram valores relativamente muito próximos entre si (TABELA 1), exceto pelo furo E-06 que apresentou uma permeabilidade da ordem de $10^{-4} \mathrm{~cm} / \mathrm{s}$. Neste furo o material descrito é uma areia média a fina.

Tabela 1 - Resultados do coeficiente de permeabilidade obtidos

\begin{tabular}{|c|c|}
\hline Ensaio & $\mathbf{K}(\mathbf{c m} / \mathbf{s})$ \\
\hline E-01 & $2,59 \times 10^{-5}$ \\
\hline E-02 & $2,00 \times 10^{-5}$ \\
\hline E-03 & $2,08 \times 10^{-5}$ \\
\hline E-04 & $2,85 \times 10^{-5}$ \\
\hline E-05 & $1,39 \times 10^{-5}$ \\
\hline E-06 & $1,71 \times 10^{-4}$ \\
\hline Média & $\mathbf{4 , 6 7 \times 1 0 ^ { - 5 }}$ \\
\hline
\end{tabular}

Conforme classificação proposta por Mello e Teixeira (1967), os dados mostram um material composto por areias finas siltosas e argilosas e siltes argilosos. A variação deste intervalo vai desde 
$10^{-3} \mathrm{~cm} / \mathrm{s}$ até $10^{-7} \mathrm{~cm} / \mathrm{s}$. Como a média calculada posiciona-se aproximadamente na metade da variação, o material apresenta uma mistura de materiais arenosos finos e argilosos.

De acordo com estudo realizado em Indicadores de Nível de água, por meio de slug tests abaixo da superfície freática, no mesmo material, foram obtidos valores bastante semelhantes aos apresentados neste estudo. No material saturado o coeficiente de permeabilidade é da ordem de $1.1 \times 10^{-5} \mathrm{~cm} / \mathrm{s}$.

Análises em testes de bombeamento realizadas por Raposo (2011) mostram que os solos residuais do CACB apresentam coeficientes de permeabilidade da ordem de $5 \times 10^{-4} \mathrm{~cm} / \mathrm{s}$

A semelhança nos dados pode ser explicada pela homogeneidade granulométrica do material analisado.

\section{CONSIDERAÇÕES FINAIS}

O método utilizado mostrou-se adequado para a determinação dos coeficientes de permeabilidade nos ensaios de poço, realizados para o minério de nióbio no Complexo Alcalino Carbonatítico do Barreiro. A vantagem desta aplicação reside no fato de ser um ensaio de fácil e rápida realização.

Os valores obtidos são relativamente semelhantes, possivelmente pelo grau de homogeneidade mineralógica e granulométrica do material, comparando-se a estudos realizados na região.

A média encontrada para os testes foi $4,67 \times 10^{-5} \mathrm{~cm} / \mathrm{s}$, o que classifica o material, com sendo composto basicamente por areias finas siltosas e argilosas e siltes argilosos. 


\section{REFERÊNCIAS BIBLIOGRÁFICAS}

ABGE. Associação Brasileira de Geologia de Engenharia. 1996. Ensaios de Permeabilidade em Solos: orientações para a sua execução no campo. 3.ed. Boletim 04. São Paulo.

ABGE. Associação Brasileira de Geologia de Engenharia. 2013. Ensaios de Permeabilidade em Solos: orientações para a sua execução no campo. 4.ed. São Paulo.

BANTON, O. 1993. Field and laboratory-determined hydraulic conductivities considering anisotropy ad core surface area. Soil Sci. Soc. of Am. v.57 (1) p. 10-15.

BAPTISTA, M.: NASCIMENTO, N.; BARRAUD, S. 2005. Técnicas compensatórias em Drenagem Urbana. Porto Alegre: ABRH.

BARBASSA, A. P.; OLIVEIRA JÚNIOR, C. X.; GUTIERREZ, L. A. R.; LUCAS, A. H. 2009. Coeficiente de permeabilidade em ensaio de poço invertido: efeito do tempo de umedecimento prévio e métodos de cálculo. In: Simpósio Brasileiro de Recursos Hídricos. Campo Grande. Anais. Campo Grande: ABRH.

CALDURO, F. A.; DORFMAN, R. (s/d). Manual de ensaios de laboratório e de campo para irrigação e drenagem. Porto Alegre: PRONI/IPH - UFRGS.

FABIAN, A. e OTTONI Filho, T. B. 1997. Determinação de curvas de infiltração usando uma Câmara de Fluxo. R. bras. Ci. Solo, Campinas.

FRANCIS, F. O. 1980. Hidráulica de meios permeáveis: escoamento em meios porosos. Rio de Janeiro: Interciência; São Paulo: Ed. Da Universidade de São Paulo.

ISSA FILHO, A.; RIFFEL, B. F.; Sousa, C. A. 2005. Some aspects of the mineralogy of CBMM Niobium Deposit and mining and pyrochlore ore processing - Araxá, MG-Brazil. Araxá: CBMM; $12 \mathrm{p}$.

LAMBE, T. W.; WHITMAN, R. V. Soil Mecanics, SI version. Massachusetts Institute of Technology. 3rd ed. New York: John Wiley \& Sons.

LIBARDI, P.L. 2000. Dinâmica da água no solo. 2. ed. Piracicaba. 509p.

MELLO, V. F. B; TEIXEIRA, A. H. 1967. Mecânica de solos. São Carlos: Escola de Engenharia. 
RAGAB, R.; COOPER J. D. 1990. Variability of unsaturated zone water transport parameters: Implications for hydrological modelling.1. In situ measurements. Journal of Hydrology. v.148.

RAPOSO, D.B., 2011. Caracterização do aqüífero associado ao Complexo Alcalino Carbonatítico do Barreiro, oeste de Minas Gerais. Dissertação de Mestrado. Universidade de Campinas. 107p.

SOUZA PINTO, C. de. 2000. Curso básico de mecânica dos solos em 16 aulas. São Paulo. Oficina de textos, $247 \mathrm{p}$.

STEPHENS, D. B. 1996. Vadose Zone Hydrology. Lewis Publishers. 


\section{ANEXO I - Planilhas de Cálculo dos Testes}

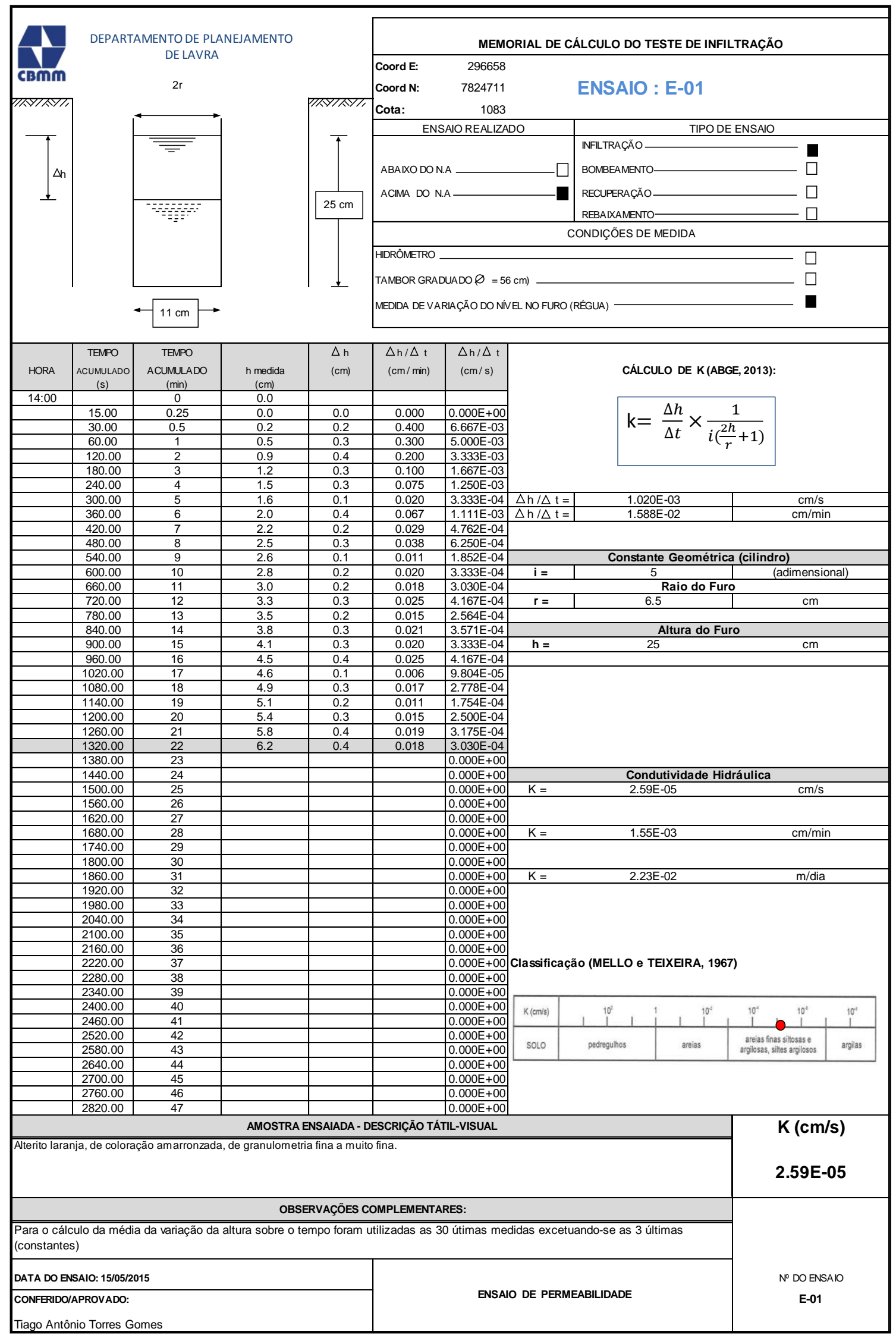




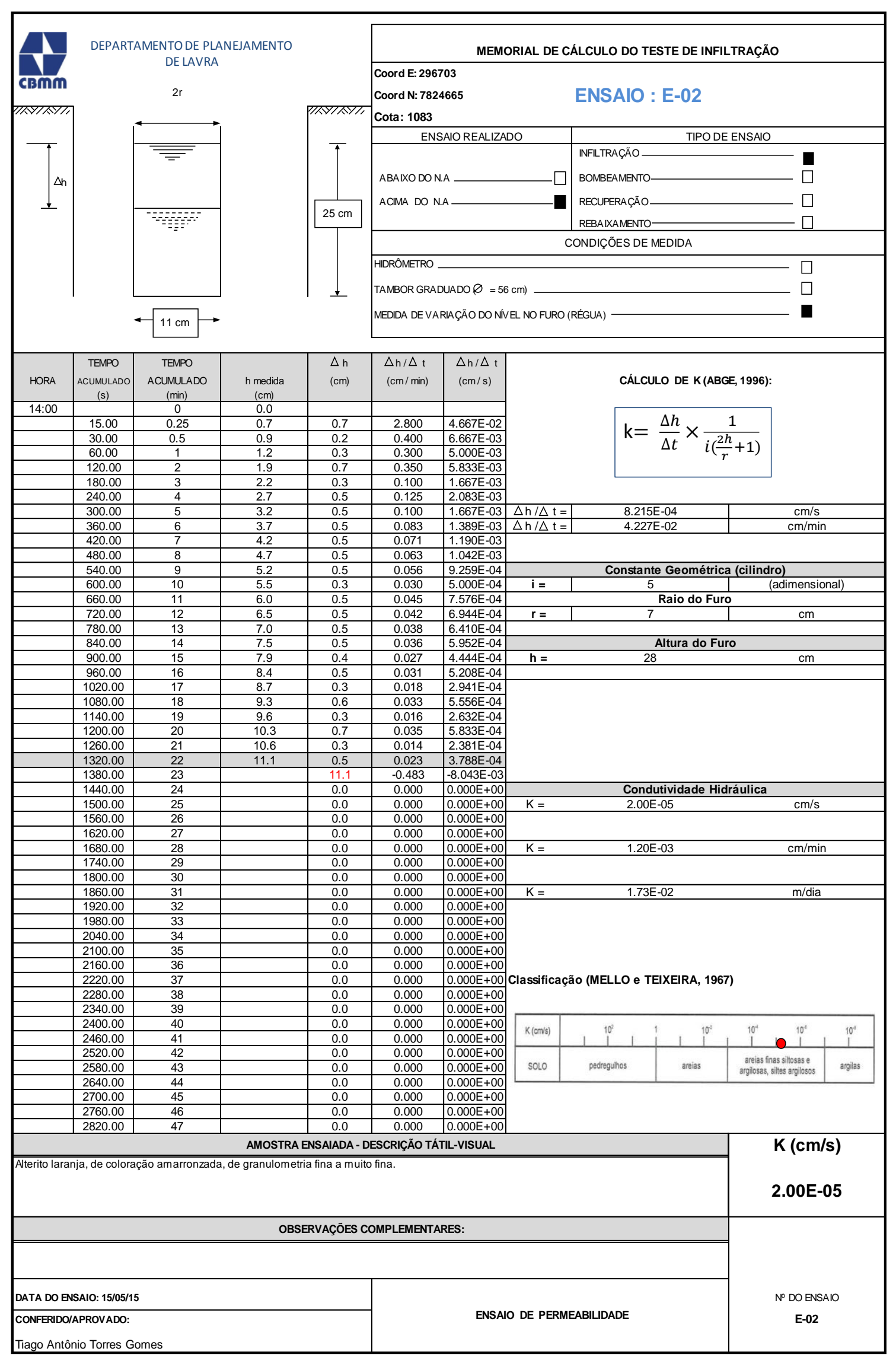




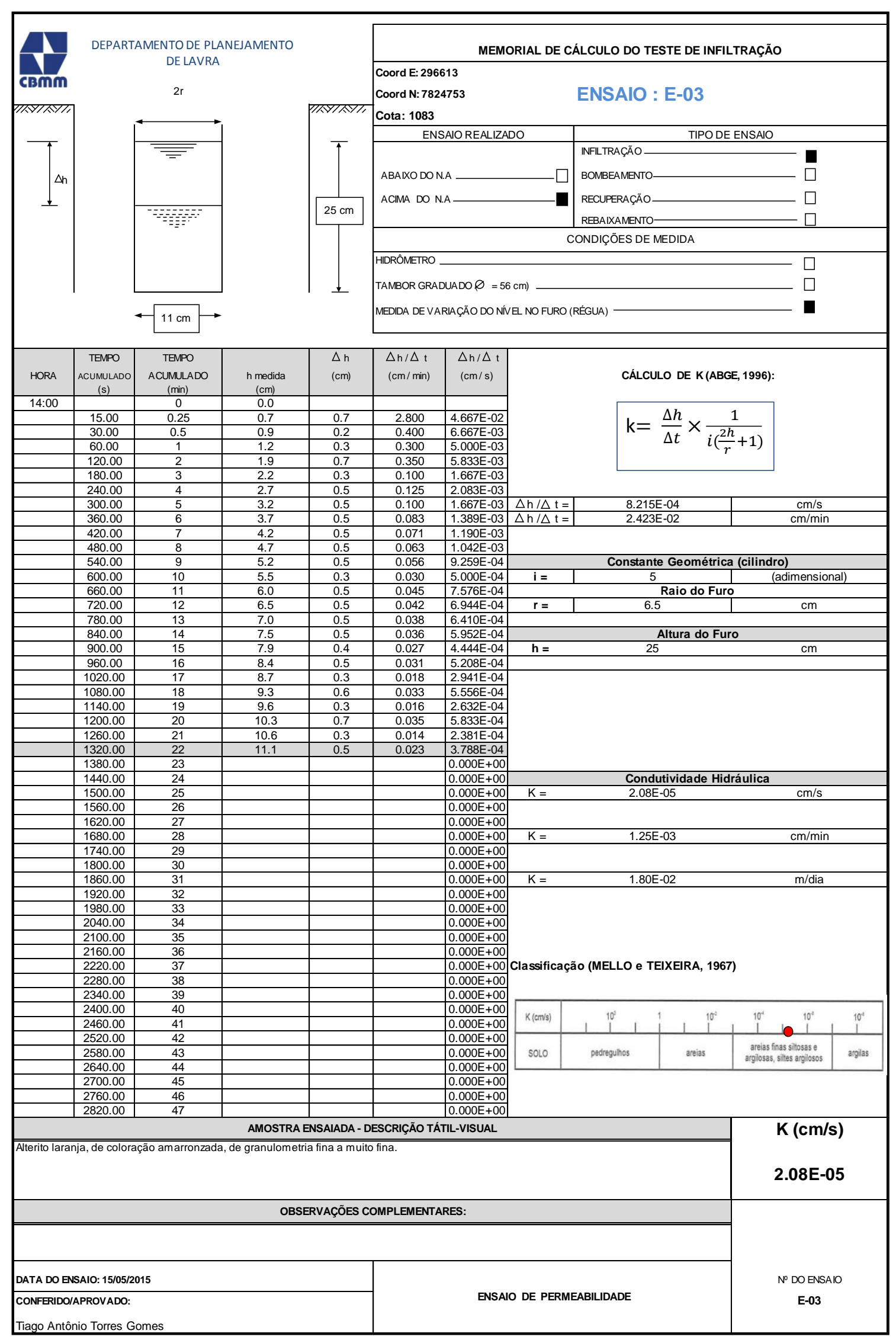




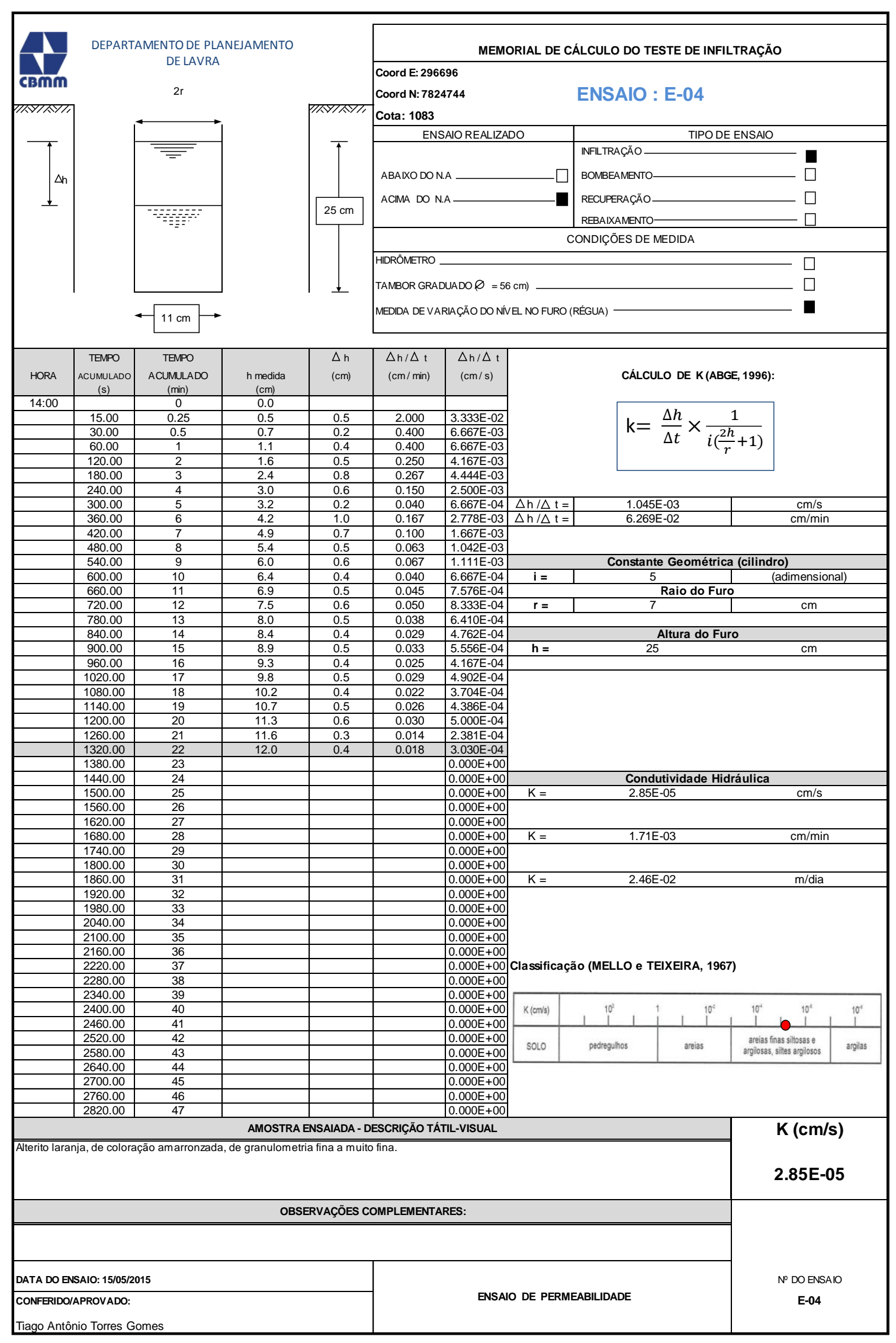




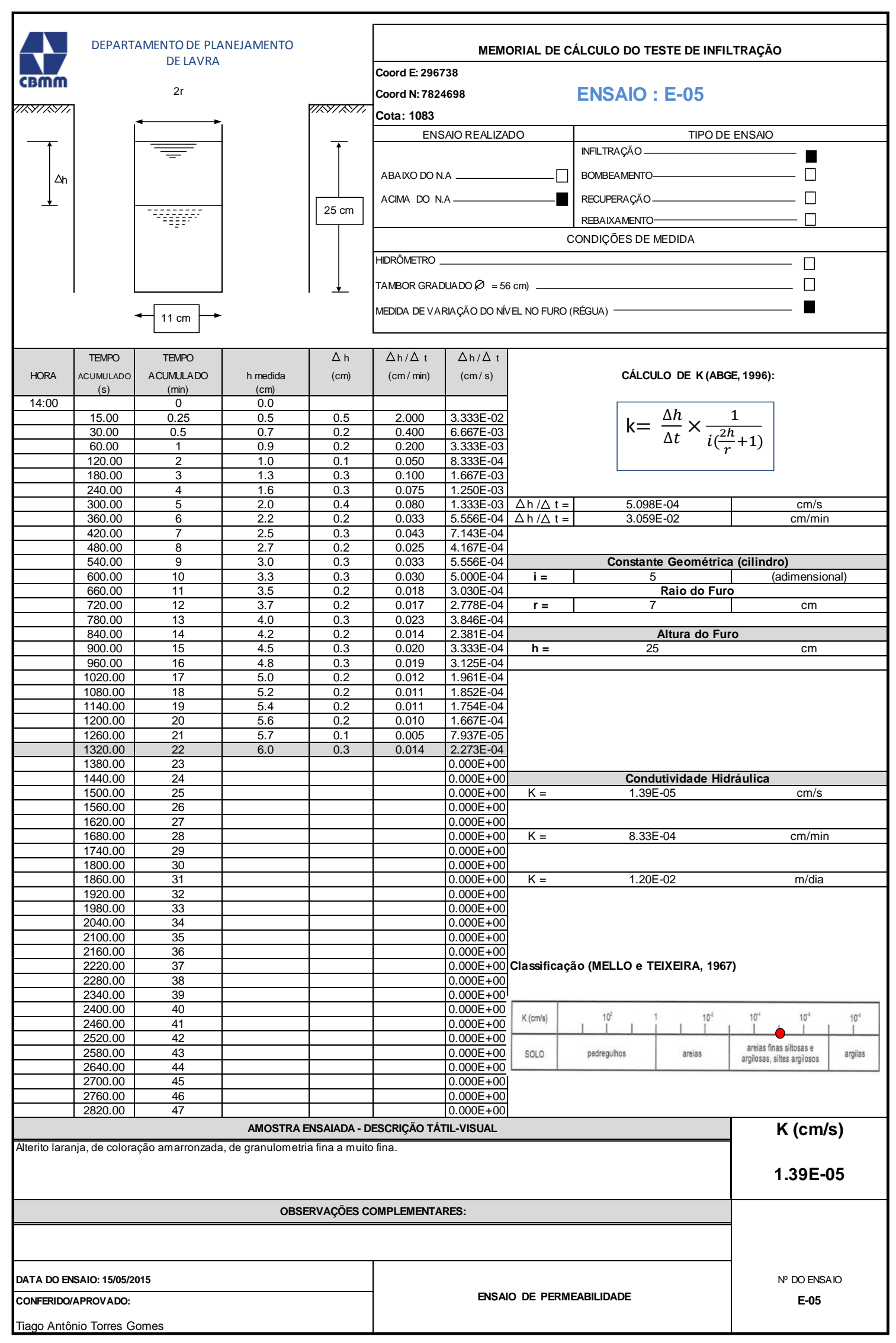




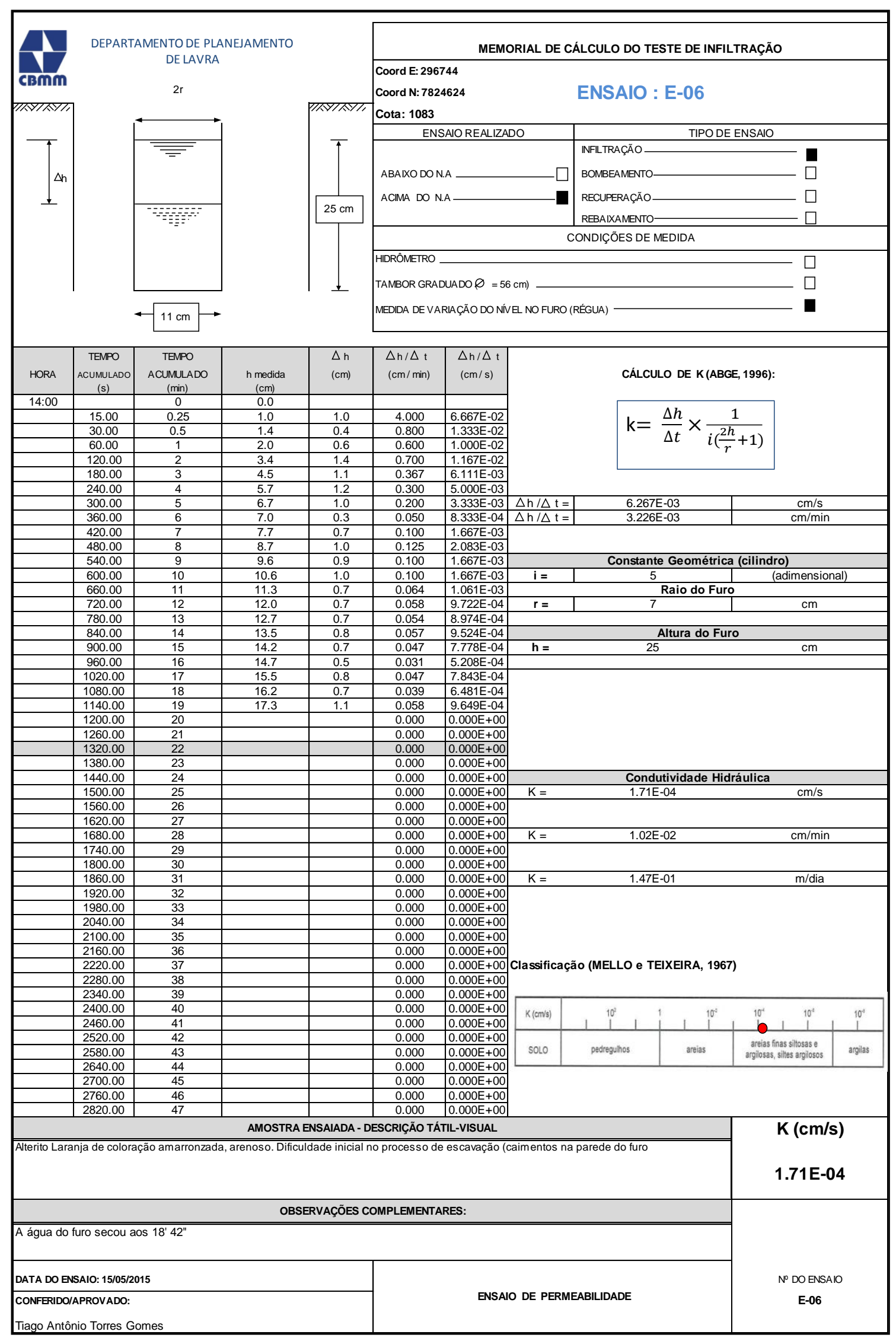

